\title{
Metapopulation structure of the marine isopod Idotea metallica, a species associated with drifting habitat patches
}

Received: 22 October 2001 / Revised: 25 July 2002 / Accepted: 28 August 2002 / Published online: 5 December 2002

(C) Springer-Verlag and AWI 2002

\begin{abstract}
The neustonic isopod Idotea metallica inhabits objects drifting at the sea surface. Animals found on floating patches represent not just ephemeral assemblages but persistent local populations. Drift material collected in the Mediterranean, the North Atlantic, and the North Sea harboured populations of up to about 50 animals including all developmental stages. In laboratory experiments the species proved to be able to establish populations on spatially limited, isolated substrates. The capacity of 5-litre-microcosms for I. metallica was about 130 animals. In the presence of the coastally distributed congener Idotea baltica, however, laboratory populations of I. metallica went extinct within 12 weeks. Even though high colonisation rates can be expected in coastal waters because of high patch densities, metapopulation persistence is mostly restricted to the open sea. In coastal waters extinction rate of local populations increases because of patch destruction and the species' inferiority to coastally distributed competitors. Due to high uncertainties in estimating patch densities, it is difficult to determine the parameters underlying metapopulation dynamics such as the migration rate and the rate of patch occupancy.
\end{abstract}

Keywords Isopods $\cdot$ Idotea metallica $\cdot$ Marine metapopulation - Competition - Surface drift material . Neuston

\section{Introduction}

Planktonic larvae disperse passively over large distances connecting seemingly isolated benthic populations.

Communicated by W. Armonies, M. Strasser and K. Reise

L. Gutow (®) - H.-D. Franke

Biologische Anstalt Helgoland,

Alfred Wegener Institute for Polar and Marine Research,

Box 180, 27483 Helgoland, Germany

e-mail: lgutow@awi-bremerhaven.de

Tel.: +49-4725-819335, Fax: +49-4725-819369
Thus, the application of the metapopulation concept poses difficulties to benthic species with pelagic larvae because discrete local populations are difficult to distinguish.

In contrast, isopods, as peracarid crustaceans, develop directly in the females' brood pouch without planktonic larval stages. Connectivity of discrete local populations occurs only temporarily and depends on active migration of the animals. Therefore isopods could be suitable target organisms for marine metapopulation research.

In addition to all kinds of benthic environments (Naylor 1972), isopods of the genus Idotea are also found associated with objects drifting at the sea surface (Franke et al. 1999). Most of the species occur only temporarily in the neustonic habitat. They become displaced to the surface accidentally, for example along with macroalgae detached from their substrate (Naylor 1955). The species Idotea metallica, however, is found exclusively on drift material, which serves as an efficient vector for the species' almost worldwide distribution (Van der Baan and Holthuis 1969; Tully and McGrath 1987). Since benthic populations ("sources") which supply neustonic assemblages ("sinks") are not known for I. metallica, the species must be expected to set up persistent breeding populations on isolated surface-drifting patches.

Most studies on metapopulations focus on fragmented but largely rigid systems. Patch densities may vary because of occasionally occurring unsuitable conditions in single patches but not because of changes in patch location. Connectivity between spatially fixed subpopulations occurs with a determinable likelihood and depends on the species' migratory capacity relative to the stable distances between the patches. In the case of I. metallica, however, metapopulation turnover is much more difficult to determine. The species is not a persistent swimmer and thus exhibits only a low capacity for active migration. The drifting patchy habitats are exposed to a high risk of destruction and show more or less random changes in density. Extreme spatial limitation and often long phases of isolation require efficient mechanisms to allow 
for high persistence of small local populations. The present paper provides information on metapopulation structure and the conditions of metapopulation persistence in I. metallica.

\section{Methods}

Field sampling

In order to determine substrate characteristics and local population sizes of I. metallica, surface drift material was collected in the German Bight (North Sea), the western Mediterranean and the North Atlantic off the West European coast. Sampling in the North Sea was conducted since 1988 in the course of a long-term monitoring programme on the isopod fauna associated with surface drift material off the island of Helgoland. Drifting objects were collected, from aboard a motor-boat, using a hand net of 1-mm mesh size (for details, see Franke et al. 1999). Material from the Mediterranean and the Atlantic was collected during a cruise of the research vessel "Heincke" in September/October 1997 from Nice (France) via Gibraltar to Helgoland. Objects were taken aboard by the use of hand nets and hooks. Sampling positions were determined by GPS. Isopods associated with drift material were counted and determined to species level.

\section{Laboratory experiments}

Because Idotea baltica exhibits a lifestyle similar to that of I. metallica, the species are likely to compete when confronted with each other. In order to analyse the outcome of this competitive interaction, population dynamics of mixed cultures of both species were observed under constant conditions $\left(16^{\circ} \mathrm{C}, 16: 8\right.$ light:dark regime). Aerated 5-litre-microcosms were stocked with 20 individuals of both species (10 juvenile males and 10 juvenile females in each), which were taken from mass cultures (Gutow and Franke 2001). $100 \mathrm{~g}$ of the brown alga Fucus vesiculosus served as a source of food and as a substrate for the animals to cling to. As I. baltica feeds excessively on brown algae, this were supplemented occasionally in order to avoid food limitation. Larvae of Artemia sp. were available ad libitum as an additional source of food. In cultures of I. metallica, the water was changed once or twice a week. Idotea baltica, however, destroyed the algae rapidly so that the resulting deterioration in water quality required the medium to be changed every second day. For this purpose, the algae with the attached animals were transferred to a new microcosm with seawater of the same temperature. Every 14 days the algae were replaced by new ones and the animals were counted. Five parallel experimental units were run as replicates.

Corresponding microcosm experiments were run to analyse population dynamics in single-species cultures (controls).

\section{Results}

\section{Field sampling}

Collected surface-drifting objects could be roughly classified into two categories:

1. "Ephemeral substrates" were represented by uprooted macroalgae, providing not only a suitable habitat for surface dwelling animals but also a valuable source of food.

2. "Persistent substrates", such as remains of fishing nets, plastic waste or timber, which are resistant to rapid natural decay.

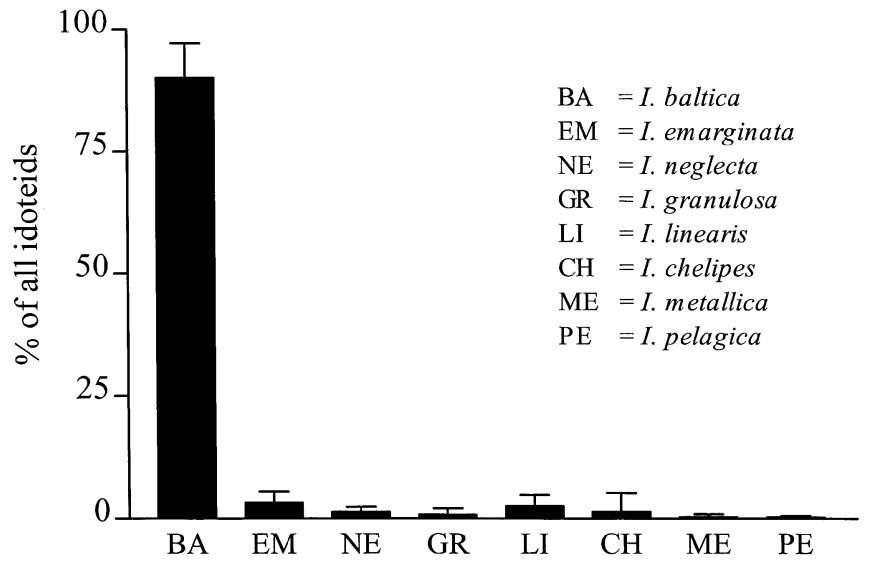

Fig. 1 Results from a 13-year study of Idotea species associated with surface drift material off Helgoland

A

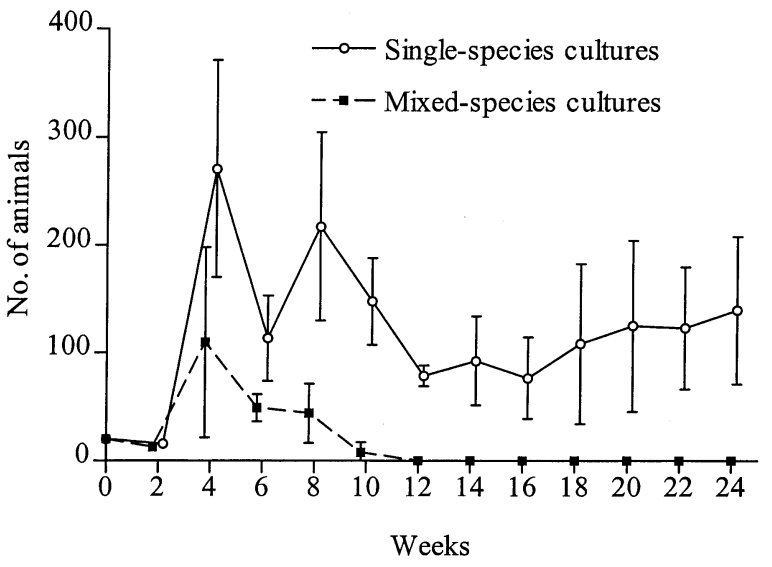

B

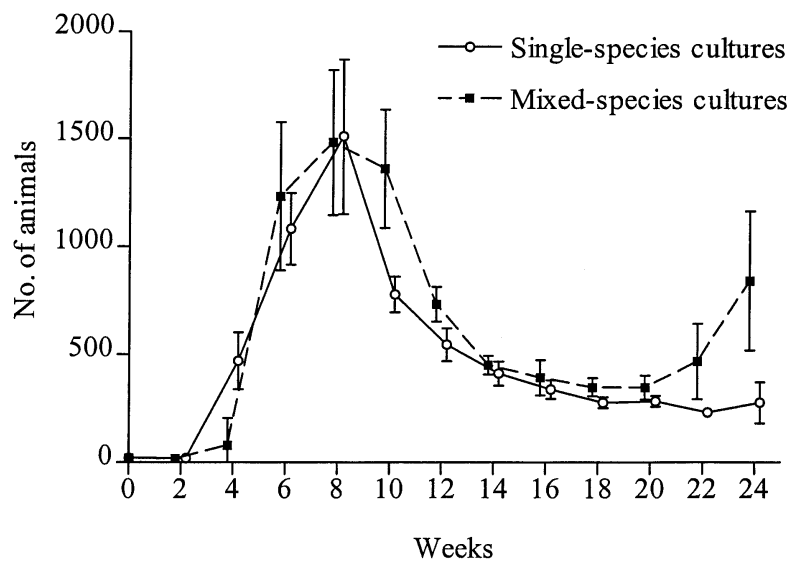

Fig. 2 Dynamics of experimental populations of I. metallica (A) and I. baltica $(\mathbf{B})$ in microcosms. Error bars denote for standard deviations (dynamics of $I$. metallica from Gutow and Franke 2001) 
Table 1 Samples containing idoteids, from the 1997 survey of RV "Heincke"

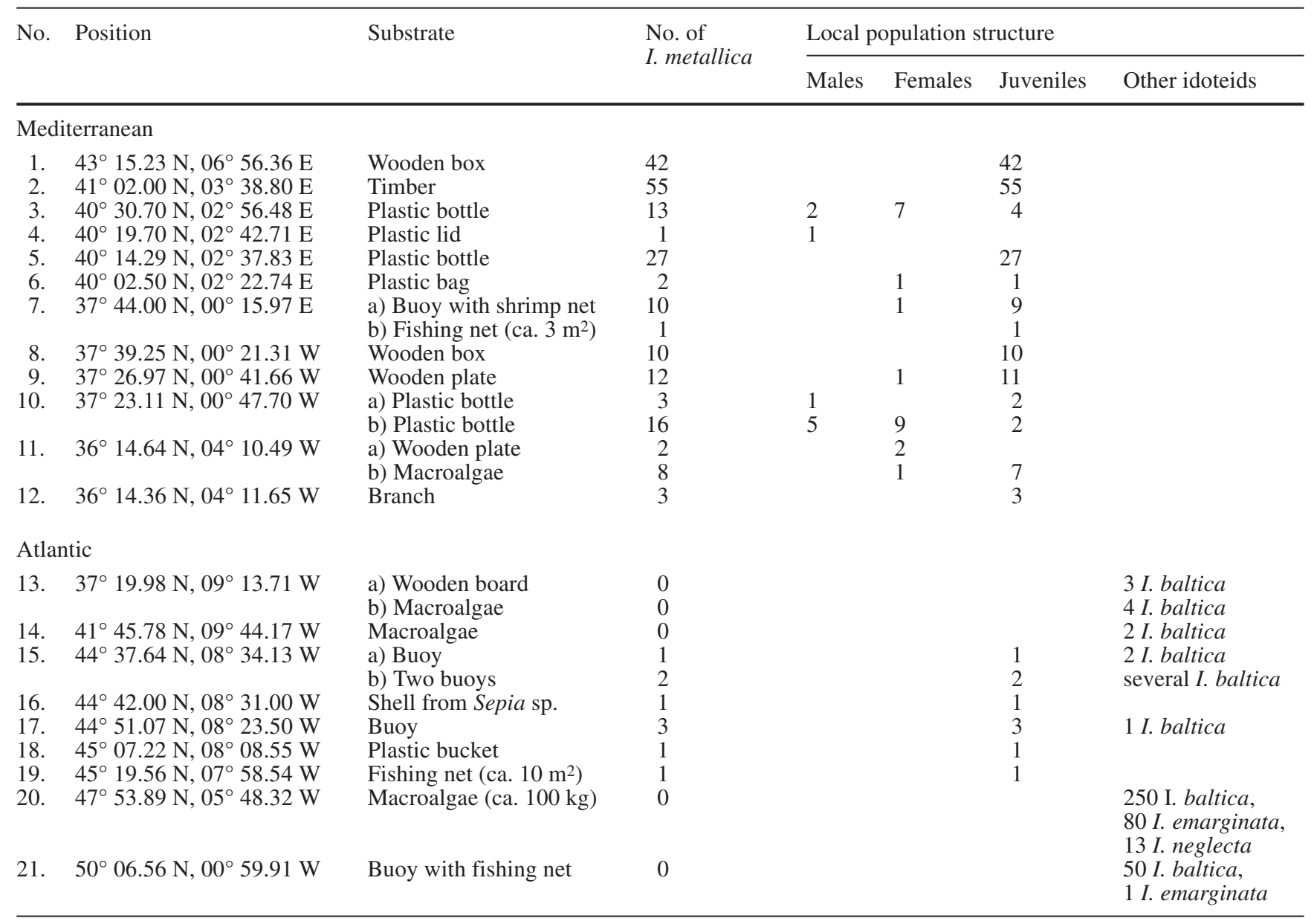

Results from Franke et al. (1999), presenting data for the sampling period 1988-1998 could be complemented until the year 2000. Eight co-existing Idotea species were recorded from surface-drifting objects in the Helgoland region (Fig. 1). Idotea baltica was the dominant species with a mean proportion of $90.1 \pm 7.1 \%$. The species was found in $109(98.2 \%)$ out of 111 samples.

Idotea emarginata, I. neglecta, I. granulosa, I. linearis, I. chelipes and I. pelagica are rather benthic species and therefore not very abundant in neustonic habitats.

Idotea metallica was first found in the German Bight in 1994. Except of the years 1996 and 1997, when I. metallica was absent from that region for climatic reasons, the species occurred with a mean proportion of $0.9 \pm 0.5 \%$ of the total Idotea community (for details, see Franke et al. 1999). Up to 40 specimens were found per sample, consisting of both adults and juveniles.

A great variety of drifting objects was collected during the cruise of RV "Heincke" in 1997 (Table 1); most, but not all, of them were harbouring isopods. In the Mediterranean, I. metallica was the only Idotea species on drifting substrates sampled at a distance offshore. Sample size varied between 1 and 55 animals per object. All developmental stages were found, including adult males, adult females and juveniles. The species was found on persistent substrates as well as on assemblages of macroalgae. In the Atlantic, I. baltica dominated on most drifting objects collected off the west coast of Europe. Large assemblages of macroalgae contained several hundred specimens per sample. Idotea metallica was found only in small numbers. The samples consisted of juveniles only.

\section{Laboratory experiments}

In single-species cultures, both species were able to establish stable populations in the microcosms (Fig. 2). In both cases population dynamics followed the classical model of a continuously reproducing species: After an initial overshoot, population density decreased and finally stabilised, oscillating at the value of the capacity $(K)$. $K$ values were about 130 animals per microcosm for I. metallica (Fig. 2A), and about 270 animals per microcosm for I. baltica (Fig. 2B).

In mixed-species cultures, population dynamics of I. baltica were not affected by the presence of I. metallica. No significant differences were observed between 
population densities under different treatments. Idotea metallica, however, was negatively affected by the presence of I. baltica in mixed-species cultures. Population density was clearly lower than in the absence of $I$. baltica. After 12 weeks, I. metallica became extinct in the microcosms.

\section{Discussion}

Except for the positive aspects of efficient dispersal, shelter from predators, and (if substrates are of biotic nature) food supply, living on surface-drifting objects exposes organisms to rather harsh conditions. Nevertheless, this special habitat provides niches for numerous species. For example, the community on drifting macroalgae in the Sargasso Sea (North Atlantic) consists of more than 100 invertebrate species (Coston-Clements et al. 1991). As a member of this community, I. metallica is well adapted to the neustonic life style. The species' worldwide distribution reveals its ability to cope with strong changes in physico-chemical parameters such as temperature and salinity. A characteristic body pigmentation different from that of benthic congeners protects the animals efficiently against high solar radiation typical for the uppermost water layer (Herring 1969). The species inhabits not only large assemblages of macroalgae but also small abiotic objects such as remains of fishing nets or plastic bottles. Due to their resistance to natural decay these substrates are important vectors for large-scale distribution by surface currents. While most studies on neustonic communities deal with samples from neuston nets, only few authors have focused on abiotic drift material as a potential habitat (e.g. Winston 1982; Barnes 2002).

Long-term persistence on isolated habitat patches requires successful reproduction and the establishment of local populations. In microcosms I. metallica proved to be able to develop stable populations under spatially limited conditions with a capacity of about 130 animals per 5 -litre vessel. Similar to these experimental populations, the samples from the Mediterranean and from off Helgoland contained all developmental stages (adult males, adult females, juveniles), indicating that the species undergoes its complete life cycle on drifting material and maintains local populations. As the respective portions of the stages varied among the samples, dynamics of the local populations were not completely synchronous. Samples consisting of only one or two animals certainly did not represent local populations. In the case of ovigerous females, however, a single specimen might be sufficient to set up a new population because broods consist of up to about 180 embryos (Abelló and Frankland 1997). Isolated males, however, might represent the remnants of a local population definitely becoming extinct in the absence of conspecifics.

As I. metallica is not a persistent swimmer, the animals are not able to migrate actively between spatially separated patches. Losing contact with the substrate will inevitably lead to sinking in the water column and most likely to death. Migration can only occur where patches accumulate. Animals then may distribute randomly over drifting objects (e.g. in their search for food), resulting in a mixing of formerly isolated local populations and occupancy of empty habitat patches.

Levins' (1969) metapopulation concept predicts a metapopulation to persist if the rate of colonisation of empty habitat patches exceeds the extinction rate of local populations. The colonisation rate depends on the distance between patches and the species' mobility. For I. metallica, a species of low migratory potential, the colonisation rate is largely determined by patch density.

High patch densities can be assumed to occur in coastal waters, where many surface-drifting objects originate from macroalgae growing in the euphotic zone of shallow waters becoming detached from the substrate by wave action or feeding activity of animals (Tully and Ó Céidigh 1986). They rise up to the surface where they provide substrates for animals to settle on. Additionally, abiotic surface-drifting waste objects are introduced, particularly into coastal waters, by man. Accumulation of drift material is favoured by the formation of characteristic boundary zones between surface currents of different speed and/or direction (Franke et al. 1999) mainly developing in coastal waters because of strong tidal currents and the impact of geological formations of the sea floor on surface currents in shallow coastal waters. Thus a maximum probability of metapopulation persistence might be expected for I. metallica in coastal waters due to a high colonisation rate resulting from both continuous supply with habitat patches and a high probability of patch accumulation.

Nevertheless, I. metallica is almost entirely absent from coastal waters. Since the species is unable to resist onshore currents actively, a continuous influx of specimens from the open sea into coastal waters must be assumed. Consequently, it is biological constraints which are likely to prevent I. metallica from establishing itself in coastal waters.

On coastally distributed drift material in the North Sea, I. baltica is the dominant isopod species (Franke et al. 1999). An encounter with I. metallica most probably results in a competitive interaction because of the species' close phylogenetic relationship and their similar life styles. In mixed-species cultures, I. baltica proved to be the superior competitor, driving I. metallica to extinction within 12 weeks. As the rather carnivorous I. metallica feeds only a little on macroalgae (personal observation) food was available in excess throughout the experimental period even though high numbers of $I$. baltica rapidly consumed the algae. Thus, competition was not primarily for resources but occurred through direct interference. The mechanism of interference was asymmetries in intra- and interspecific predation of juveniles by adults, as it is also known from competition between I. baltica and I. emarginata (Franke and Janke 1998).

Another process which may affect I. metallica even more severely and rapidly than interference is habitat de- 


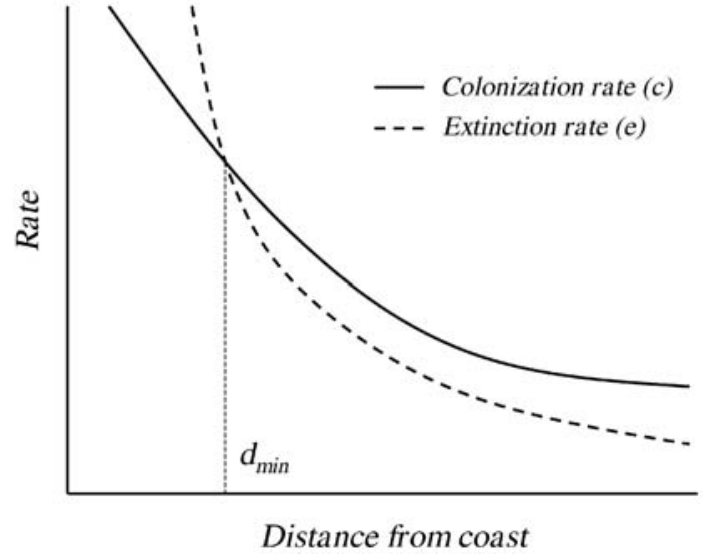

Fig. 3 Model for metapopulation persistence as a function of distance from the coast

struction. Patches entangled in coastal current systems are exposed to a high risk of being washed ashore. Additionally, I. baltica is known to feed intensively on macroalgae (Engkvist et al. 2000). After complete patch destruction, the latter species is able to shift from a neustonic to a benthic life style in coastal waters (Locke and Corey 1989). Idotea metallica, however, as a euneustonic species, is not able to develop benthic populations (Olivar et al. 1998). After losing shelter from drifting patches, the animals are most probably preyed upon rapidly by fish (Tully and McGrath 1987; Deudero and Morales-Nin 2000) or seabirds (Furness and Todd 1984) or will die of exhaustion while swimming around in search of new patches. Even if specimens succeed in finding nearby patches, they will stay in a coastal system where a population finally must become extinct because of competitive inferiority to I. baltica.

In a simple model (Fig. 3) for species living under conditions similar to I. metallica, both the colonisation rate $(c)$ of empty habitat patches and the extinction rate $(e)$ of local populations decline with increasing distance to the coast. While near to the coast, the extinction rate exceeds the colonisation rate; the situation is the reverse far offshore. The point of intersection $(c=e)$ represents the minimum distance $\left(d_{\min }\right)$ to the coast required for metapopulation persistence. Since I. metallica is dispersed ocean-wide (i.e. from North America to Europe), an offshore limit for metapopulation persistence does not seem to exist for this species. Most likely, accumulation of patches is favoured offshore by current systems such as Gulf Stream rings (Backus et al. 1981), facilitating colonisation and, thus, metapopulation persistence.

Although there are occasional sightings of I. metallica from many parts of the world, two major distribution areas can be identified: the Mediterranean and the North Atlantic. With respect to surface currents, the Mediterranean is a rather closed system, with I. metallica reproducing almost the whole year under subtropical temperatures. Due to these hydrographic and climatic conditions, the Mediterranean metapopulation of I. metallica appears (at a coarse scale) spatially and temporally homo- geneous compared with the North Atlantic metapopulation. While I. metallica occurs permanently off the east coast of North America (and perhaps along the entire Gulf Stream) the species is found only temporarily in European waters, with local extinction in winter. Even though the species must be expected to be continuously introduced into European waters in small numbers, local populations cannot persist in winter because temperatures are too low for reproduction (Gutow and Franke 2001). This seasonal extinction of local populations in an area causes spatial fluctuations of the extension of the metapopulation.

Distinct local populations on drifting habitat patches can be considered as a special case of a metapopulation which can only be found in the marine environment. In limnic systems, too, animals may inhabit drift material but, due to the spatial limitation of lakes, accumulation of drifting objects occurs quite frequently. Thus intensive migration between patches may lead to a heterogeneous population rather than to a metapopulation. A parasite-host system with local populations of a parasite inhabiting different individuals of a mobile host, such as fleas inhabiting mammals, may represent a situation comparable to that discussed here. But accumulation of "patches" is much less accidental in this case because host individuals come together (e.g. for mating), or avoid each other, actively.

The fundamental problem in estimating parameters relevant for metapopulation dynamics, such as extinction rate, colonisation rate or occupancy of habitat patches, is a lack of knowledge about the distribution of drifting objects. Surface currents change (especially in coastal waters) with wind direction, wind force and tides. Additionally, boundary zones between surface currents of different speed and direction favouring accumulation of drift material vary significantly in position and shape. Longterm surveys on density and distribution of drifting objects may provide a crude estimate of the mean distance between patches and the local probability of patch accumulation. These estimates could be used to develop a spatially explicit metapopulation model (Hanski and Gilpin 1991) with locally varying distances between the nodes of the grid in which the patches are arranged corresponding to local patch densities.

Estimating the probabilities of metapopulation persistence for species associated with drifting objects might be useful for conservation biology and research on biological diversity. As this habitat represents an efficient vector for the dispersal of species, assumptions can be made about the probabilities, mechanisms, and consequences of an introduction and establishment of non-indigenous species.

Acknowledgements Special thanks to the crew of RV "Heincke" and to M. Janke for his contribution to the sampling of Idotea. 


\section{References}

Abelló P, Frankland RJ (1997) Population characteristics of the neustonic isopod Idotea metallica (Crustacea, Isopoda, Idoteidae) in the western Mediterranean (June 1993). Sci Mar 61:409-414

Backus RH, Flierl GR, Kester DR, Olson DB, Richardson PL, Vastano AC, Wiebe PH, Wormuth JH (1981) Gulf stream cold-core rings: their physics, chemistry, and biology. Science 212:1091-1100

Barnes DKA (2002) Invasions by marine life on plastic debris. Nature 416:808-809

Coston-Clements L, Settle LR, Hoss DE, Cross, FA (1991) Utilization of the Sargassum habitat by marine invertebrates and vertebrates: a review. NOAA Technical Memorandum NMFSSEFSC-296

Deudero S, Morales-Nin B (2000) Occurrence of Polyprion americanus under floating objects in western Mediterranean oceanic waters, inference from stomach contents analysis. J Mar Biol Assoc UK 80:751-752

Engkvist R, Malm T, Tobiasson S (2000) Density dependent grazing effects of the isopod Idotea baltica Pallas on Fucus vesiculosus L in the Baltic Sea. Aquat Ecol 34:253-260

Franke HD, Janke M (1998) Mechanisms and consequences of intra- and interspecific interference competition in Idotea baltica (Pallas) and Idotea emarginata (Fabricius) (Crustacea: Isopoda): a laboratory study of possible proximate causes of habitat segregation. J Exp Mar Biol Ecol 227:1-21

Franke HD, Gutow L, Janke M (1999) The recent arrival of the oceanic isopod Idotea metallica Bosc off Helgoland (German Bight, North Sea): an indication of a warming trend in the North Sea? Helgol Meeresunters 52:347-357

Furness RW, Todd CM (1984) Diets and feeding of fulmars Fulmaris glacialis during the breeding season: a comparison between St Kilda and Shetland colonies. Ibis 126:379-387
Gutow L, Franke HD (2001) On the current and possible future status of the neustonic isopod Idotea metallica Bosc in the North Sea: a laboratory study. J Sea Res 45:37-44

Hanski I, Gilpin M (1991) Metapopulation dynamics: brief history and conceptual domain. In: Gilpin M, Hanski I (eds) Metapopulation dynamics: empirical and theoretical investigations. Academic Press, London, pp 3-16

Herring PJ (1969) Pigmentation and carotinoid metabolism of the marine isopod Idotea metallica. J Mar Biol Assoc UK 49: 766-779

Levins R (1969) Some demographic and genetic consequences of environmental heterogeneity for biological control. Bull Entomol Soc Am 15:237-240

Locke A, Corey S (1989) Amphipods, isopods and surface currents: a case for passive dispersal in the Bay of Fundy, Canada. J Plankton Res 11:419-430

Naylor E (1955) The ecological distribution of British species of Idotea (Isopoda). J Anim Ecol 24:255-269

Naylor E (1972) British marine isopods. (Synopsis of the British fauna, new series, no 3) Academic Press, London

Olivar MP, Sabates A, Abelló P, Garcia M (1998) Transitory hydrographic structures and distribution of fish larvae and neustonic crustaceans in the north-western Mediterranean. Oceanol Acta 21:95-104

Tully O, McGrath D (1987) The status of Idotea metallica Bosc (Isopoda) in Irish waters. Ir Nat J 22:190-192

Tully O, Ó Céidigh P (1986) The ecology of Idotea species (Isopoda) and Gammarus locusta (Amphipoda) on surface driftweed in Galway Bay (West of Ireland). J Mar Biol Assoc UK 66:931-942

Van der Baan SM, Holthuis LB (1969) On the occurrence of Isopoda in the surface plankton in the North Sea near the lightship "Texel”. Neth J Sea Res 4:354-363

Winston J (1982) Drift plastic: an expanding niche for a marine invertebrate? Mar Pollut Bull 13:348-351 